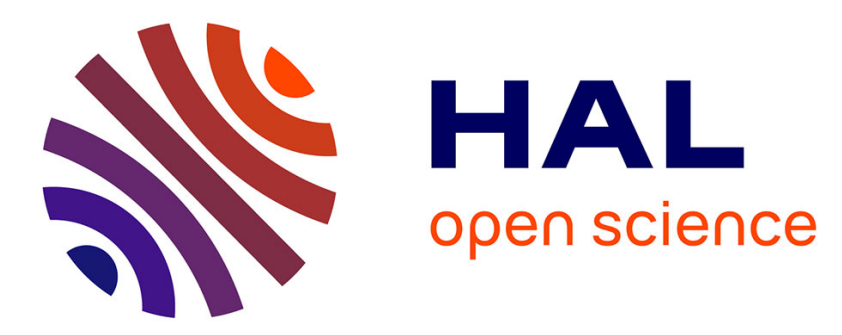

\title{
Amylose chain behavior in an interacting context II. Molecular modeling of a maltopentaose fragment in the barley $\alpha$-amylase catalytic site
}

\author{
Gwenaëlle André-Leroux, Alain Buleon, R. Haser, Vinh Tran
}

\section{To cite this version:}

Gwenaëlle André-Leroux, Alain Buleon, R. Haser, Vinh Tran. Amylose chain behavior in an interacting context II. Molecular modeling of a maltopentaose fragment in the barley $\alpha$-amylase catalytic site. Biopolymers, 1999, 49 (1), pp.107-119. 10.1002/(SICI)1097-0282(199901)49:13.0.CO;2-S . hal02695382

\section{HAL Id: hal-02695382 \\ https://hal.inrae.fr/hal-02695382}

Submitted on 1 Jun 2020

HAL is a multi-disciplinary open access archive for the deposit and dissemination of scientific research documents, whether they are published or not. The documents may come from teaching and research institutions in France or abroad, or from public or private research centers.
L'archive ouverte pluridisciplinaire HAL, est destinée au dépôt et à la diffusion de documents scientifiques de niveau recherche, publiés ou non, émanant des établissements d'enseignement et de recherche français ou étrangers, des laboratoires publics ou privés. 


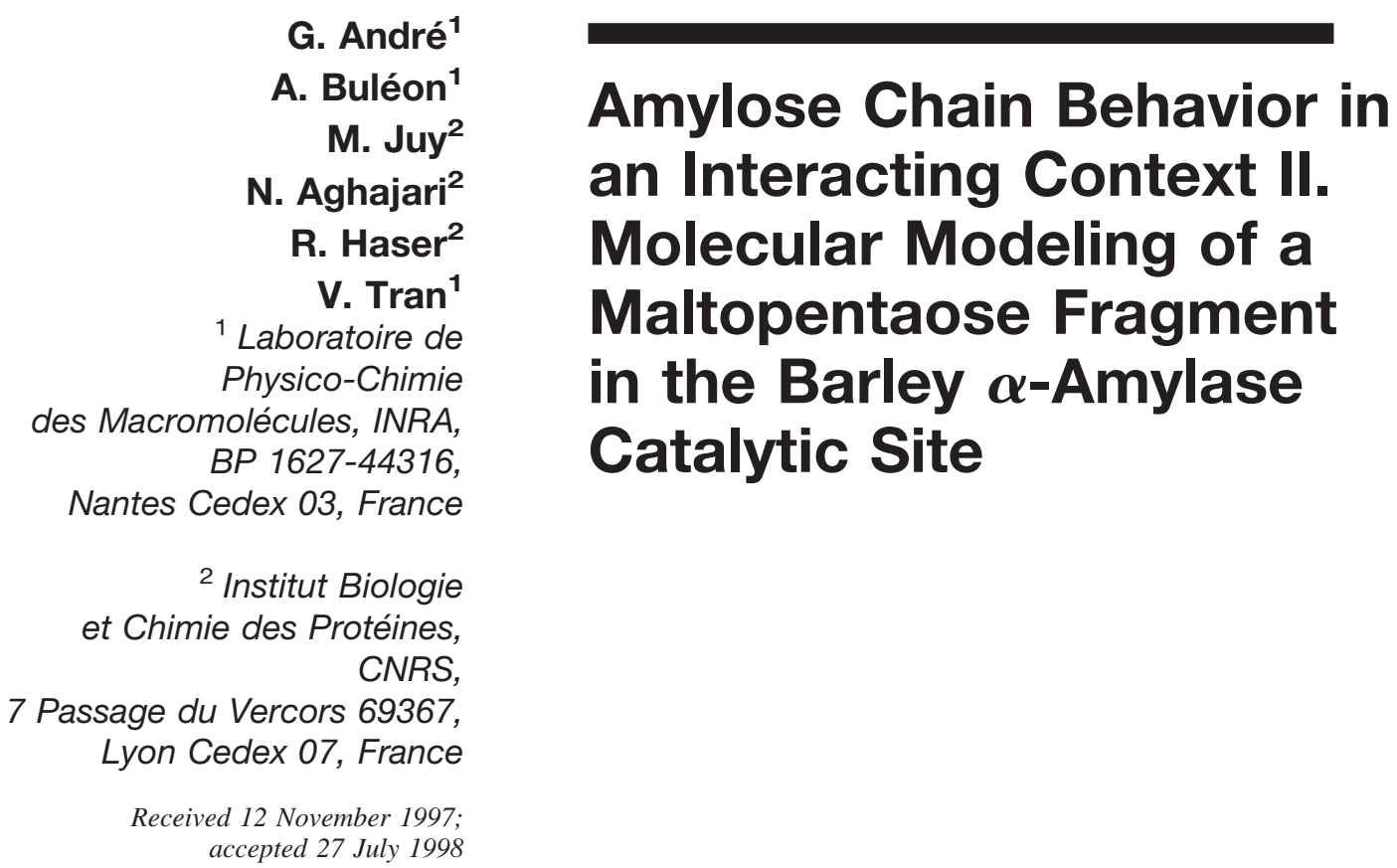

\begin{abstract}
In the first paper of this series, the tools necessary to evaluate the consequences of glucopyranose ring deformations in terms of glycosidic torsion angle shifts, and amylose chain propagation have been created. In this second paper, the modeling of amylose fragments into the catalytic region of barley $\alpha$-amylase has been performed by a systematic approach. From the crystal data of the acarbose/amylase complex, maltotriose and maltopentaose fragments have been docked in the catalytic cleft. It has been found that for the trisaccharide, no substrate ring deformation is needed to respect stacking interactions (with Y51 and W206) characteristic of the substrate binding. However, for the pentasaccharide the deformations of rings $\mathbf{A}$ and $\mathbf{C}$ (from chair $\{\mathbf{C}\}$ toward half-chair $\{\mathbf{H 2}\}$ and skew $\{\mathbf{S 4}\}$, respectively) are essential conditions to fit this amylose fragment into the narrow catalytic site. Within five contiguous binding subsites, all important enzyme residues have been listed, which is of great importance for the understanding of the cleavage mechanism or any further biochemical modification. The best energy docking solution that was found is consistent with experimental data. (C) 1999 John Wiley \& Sons, Inc. Biopoly 49: 107-119, 1999
\end{abstract}

Keywords: amylose; chain behaviors; molecular modeling; maltopentaose; barley; $\alpha$-amylase; cataly sp.

\section{INTRODUCTION}

$\alpha$-Amylase (EC 3.2.1.1) catalyzes the hydrolysis of $\alpha-(1,4)$ glycosidic linkages in starch components (amylose and amylopectin), glycogen, or products derived therefrom. These amylolytic enzymes are widely distributed in the living organisms and are largely used in industrial processes. A better under-

Correspondence to: V. Tran

Biopolymers, Vol. 49, 107-119 (1999)

(C) 1999 John Wiley \& Sons, Inc.

CCC 0006-3525/99/010107-13 
standing of the $\alpha$-amylase/amylose interactions preliminary necessitates structural information about the two partners.

\section{Barley $\alpha$-Amylase}

Most accurate structural knowledge on $\alpha$-amylases is provided by x-ray data and several crystal structures have been solved from Aspergillus oryzae (TAKA amylase $)^{1}$ at 3 then at $2.1 \AA$ resolution, ${ }^{2}$ from porcine pancreas (PPA) at $2.9 \AA$ (Ref. 3) then at $2.1 \AA$ resolution, ${ }^{4,5}$ and from Aspergillus niger ${ }^{6,7}$ at $2.1 \AA$ resolution. More recently, other structures have been solved from Bacillus licheniformis ${ }^{8}$ at $2.2 \AA$ resolution, from human pancreas ${ }^{9}$ at $1.8 \AA$ resolution, from human saliva at $2.8 \AA$ (Ref. 10) then at $1.6 \AA$ resolution, ${ }^{11}$ and from Alteromonas haloplanctis at 2.0 and $1.85 \AA$ A resolution. ${ }^{12}$

In the barley seeds, two $\alpha$-amylase isozymes, the low pI (AMY1) and the high pI (AMY2) forms, are synthesized during germination. The complete amino acid sequences ${ }^{13,14}$ of the mature proteins are known and show a sequence identity of about $75 \%$. AMY1 and AMY2 contain, respectively, 414 and 403 amino acid residues. ${ }^{13,15,16}$ Despite their high degree of homology, AMY1 and AMY2 possess distinct physical and chemical properties, such as calcium ion affinity, ${ }^{17-19}$ sulfhydryl and chelating reagents sensitivity, stability at acidic $\mathrm{pH},{ }^{19,20}$ and high temperature, activity toward starch granules ${ }^{21,22}$ and affinity for soluble substrates. ${ }^{23-25}$ This could explain their different physiological roles. From a comparison between five sequences of $\alpha$-amylases, MacGregor ${ }^{26}$ has found that only 20 residues are identical. More generally, Svens$\operatorname{son}^{27}$ has compared amylases, $\alpha$-glucosidases, and transglucanases, and a low degree of homology has been revealed. But Friedberg has also evoked ${ }^{28}$ that, as for serine proteases, some carbohydrate hydrolases could have a similar arrangement of the catalytic site despite non homologous sequences.

For barley $\alpha$-amylase, the three-dimensional structure of isoform AMY2.2 has been solved at $2.8 \AA$ resolution. ${ }^{29,30}$ This enzyme is a monomeric and calcium-dependent enzyme with a polypeptide chain folded into three domains. ${ }^{29,31}$ Central domain A has the characteristic $(\alpha / \beta)_{8}$-barrel structure. ${ }^{32,33}$ Domain $\mathrm{B}$ is inserted between $\beta$-sheet 3 and helix 3 (Ref. 34) and forms a long loop involved in the binding of both the substrate and the calcium ions. ${ }^{24,35}$ Finally, a distinct globular $\mathrm{C}$ domain, consisting of 5 antiparallel $\beta$-sheets, is located at the C-terminal end of domain $\mathrm{A}$ but its function is not clearly understood yet. The catalytic site is located in a cleft, adjacent to a)

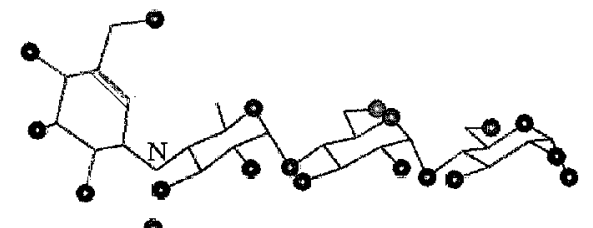

b)

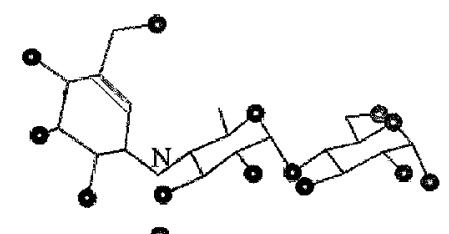

c)
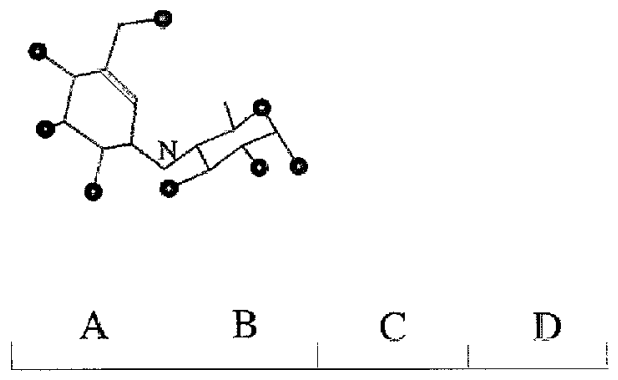

FIGURE 1 Schematic representation of acarbose (a), truncated acarbose (b), and acarviosine (c). Ring labeling $(\mathbf{A}, \mathbf{B}, \mathbf{C}, \mathbf{D})$ is consistent with that used in the text. Ball representation refers to oxygen atom.

domains A and B. From specific residue mutations on AMY $1,{ }^{36}$ it has been deduced that the effective catalytic residues for AMY2 are E204, D179, and D289. More generally, a catalytic scheme has been developed, suggesting that the active regions can be divided in contiguous subsites, each one capable of interacting with glucopyranose rings (called glucose in this text). In cereal $\alpha$-amylases, 10 subsites have been determined by biochemical techniques. ${ }^{24,37}$

\section{Amylose Chain}

For the amylose chain, the essential feature is the possible deformation of one glucose ring at the vicinity of the catalytic site that has been related in detail in the previous paper $^{38}$ (called paper I in this text). Since paper I is essential for the understanding of six-membered ring deformations, the definitions and tools previously developed will be systematically used here. Ring A of acarbose (Figure 1a) is a prototypical model of the glucose deformation. In the PPA/ acarbose complex, the crystal structure ${ }^{5}$ reveals that the cyclitol ring adopts a half-chair conformation $\{\mathbf{H}\}$. Similarly, for barley $\alpha$-amylase, the complex formed with acarbose (Figure $1 \mathrm{~b}$ ) $29,30,35$ shows a strong deformation for one ring in the acarviosine moiety (Figure 1c).

The acarbose pseudo-tetrasaccharide (Figure 1a) is a strong inhibitor of $\alpha$-amylases. The conformation of 
the acarviosine fragment could be responsible for this excellent binding with the enzyme. On the one hand, the presence of a double bond in the nonreducing ring leads to an almost planar ring form that apparently fits well the available room around the catalytic triad. As suggested by many authors, ${ }^{39,40}$ this inhibitor conformation could mimic an intermediate state because the flattening of the glucose ring is necessary at least in the two most common mechanisms proposed-either a covalent enzyme-glycosyl intermediate ${ }^{41,42}$ or an oxocarbonium ion transition state ${ }^{43}$-although both states could be involved. ${ }^{44}$ On the other hand, the nitrogen atom prevents the hydrolysis and therefore gives a satisfactory snapshot of the short-lived transition state. As a major consequence of this ring deformation, the pseudo-glycosidic torsion angles $\left(\varphi^{\prime}\left[\mathrm{C}_{7}-\mathrm{C}_{1}-\mathrm{N}_{1}-\mathrm{C}_{4}\right]\right.$ and $\left.\psi^{\prime}\left[\mathrm{C}_{1}-\mathrm{N}_{1}-\mathrm{C}_{4}-\mathrm{C}_{5}\right]\right)$ adjacent to this ring have unexpected values compared to those $\left(\varphi\left[\mathrm{O}_{5}-\mathrm{C}_{1}-\mathrm{O}_{1}-\mathrm{C}_{4}^{\prime}\right], \psi\left[\mathrm{C}_{1}-\mathrm{O}_{1}-\right.\right.$ $\left.\mathrm{C}_{4}^{\prime}-\mathrm{C}_{5}^{\prime}\right]$ ) calculated for the low energy conformations from a maltose model (map $\{\boldsymbol{C}-\boldsymbol{C}\}{ }^{45,46}$ These torsion angles are all the more important as they are directly related to the chain propagation.

\section{PROTOCOLS}

The molecular modeling studies have been carried out on Silicon Graphics computers with MSI packages (San Diego, CA, USA). Molecular displays and energy minimization have been performed with the Insight II, Biopolymer, and Discover modules. For all calculations, the force field $\mathrm{CFF} 91^{47}$ has been selected.

\section{Starting Enzyme and Substrate Geometries}

The coordinates of the acarbose/AMY2-2 complex $^{29,30}$ are the starting point of this modeling study. For the enzyme, a substructure has been artificially defined including all interesting residues of the catalytic site or delimiting the cleft (likely to be in contact with the substrate). All corresponding backbone heavy atoms have been kept rigid through out the calculations except in final stages where they have been allowed to relax to adjust the amylose fragments. From this core, an outer region of about $20 \AA$ thickness has also been considered by adding the corresponding residues. In this external region, all residues have been frozen in the minimization procedures to facilitate the junction between the flexible catalytic site and the rest of the enzyme. In total, an ensemble of 55 residues and 3 calcium ions have been taken into account for the energy calculations, which represents about one eighth of the enzyme.

Acarbose has been the starting point for the construction of successive substrate fragments. For sake of comparison with further modeled substrate fragments, this molecule has been minimized (500 iterations, fixed heavy atom coordinates of the enzyme) in the catalytic environment. In this paper, the ring labeling of the substrate molecules has been kept consistent to that employed for this inhibitor-named $\mathbf{A}$, $\mathbf{B}$, and $\mathbf{C}$ from nonreducing to reducing ends. With this nomenclature,* ring $\mathbf{A}$ is the most planar and the cleavage occurs between rings $\mathbf{A}$ and $\mathbf{B}$. For the sake of consistency, this labeling can be transposed to the subsite numbering found in the literature, ${ }^{24,37,48}$ which is also based on the cleavage location. Thus, binding subsites $(\mathbf{- 1}, \mathbf{+ 1}$, and $\mathbf{+ 2}$ ) are occupied by rings $(\mathbf{A}, \mathbf{B}$, and $\mathbf{C})$ respectively.

\section{Modeling Strategy}

Because of the high number of degrees of freedom when taking into account the intrinsic flexibility of both molecular entities, the false minima risks are always present in docking calculations. According to the previous work (paper I), all low energy conformations of the maltose, with or without glucose deformation at reducing or nonreducing end, have been checked off. Therefore, starting from all these geometries, minimizations have been carried out and low energy solutions have been selected. The minimization steps have been used to refine the internal parameters with or without external constraints at intermediate stage to fully or partially restrain the mobility of specific parts in the molecular system. However, for sake of comparison, such constraints have been released at the final minimization stage. This systematic docking approach should sample the corresponding conformational phases much better than a simulated annealing procedure (such as molecular dynamics + energy minimization).

In our protocol, the construction of substrate fragments has been closely related to subsequent energy calculations. The virtual "growth" of the substrate has been achieved by a unit per unit propagation scheme and the validity of each construction step in the catalytic environment has been confirmed by exhaustive calculations. This kind of approach has been made

* In the following text, the capital bold characters (i.e., $\mathbf{A}$ or $\mathbf{C}$ ) are used for the ring labeling, while capital, bold, and italic characters (i.e., $\{\boldsymbol{C}\}$ or $\{\boldsymbol{S} \boldsymbol{x}\}$ ) are reserved for the ring forms. Finally, capital characters (i.e., A or E) refer to the low energy domains of the maltose maps. 
possible with the assumption that the added rings are docked on contiguous subsites.

Binding of a Maltotriose Fragment. The building of the trisaccharide fragment has been performed, free from any experimental presumption, as for example the ring $\mathbf{A}$ deformation. It has only been postulated that ring $\mathbf{B}$ adopts the stable $\{\boldsymbol{C}\}$ form because no experimental data revealed any other ring conformation in subsite $(+\mathbf{1})$ of $\alpha$-amylases. As an illustration, the maltose construction will be explained in detail. From the $\{\boldsymbol{C}\}$ form for ring $\mathbf{B}$, another ring (labeled $\mathbf{C}$ ) has been added with forms $\{\boldsymbol{C}\}$ or $\{\boldsymbol{S} \boldsymbol{x}\}$. According to the previous work, the low energy conformations of fragment $\mathbf{B}-\mathbf{C}$ can be located on the $(\varphi, \psi)$ maps of types $\{\boldsymbol{C}-\boldsymbol{C}\}$ or $\{\boldsymbol{C}-\boldsymbol{S} \boldsymbol{x}\}$, depending on the ring $\mathbf{C}$ form. For example, from map $\{\boldsymbol{C}-\boldsymbol{C}\}$ (see Figure 4, paper I), four starting maltose conformations (domains $\mathrm{A}, \mathrm{B}, \mathrm{C}$, and $\mathrm{E}$ ) have been extracted for further minimizations. When ring $\mathbf{C}$ initially adopts a $\{\boldsymbol{S} \boldsymbol{x}\}$ form, the number of starting geometries for fragment B-C is much more important because six maps have to be considered- $\{\boldsymbol{C}-\boldsymbol{S 1}\}$ to $\{\boldsymbol{C}-\boldsymbol{S} \boldsymbol{6}\}$ (see Figure 6, paper I)-from which three or four low energy conformations should be tested in the catalytic context. Then, these starting geometries have been anchored inside the catalytic cleft by superimposing ring $\mathbf{B}$ to that of the inhibitor.

Each docking solution has been obtained with two successive minimization procedures. The first minimization (500 iterations) has been performed by tethering the substrate atomic coordinates (template force constant of $100 \mathrm{kcal} \cdot \mathrm{A}^{-2}$ ) and fixing all enzyme heavy atoms. The goal of this first step was to adapt progressively the initial substrate geometry to its rigid enzyme environment. In the second minimization (1000 iterations), all the constraints on the substrate have been removed for a full relaxation of the conformational parameters. Then, the resulting docking has been evaluated with the potential energy of the system (enzyme + substrate), which essentially takes into account the substrate energy conformation but also its adaptation in the catalytic site. The lowest energy solution has been kept for subsequent constructions.

The same construction protocol has been used for maltotriose by adding ring $\mathbf{A}$ to refined fragment $\mathbf{B}-\mathbf{C}$ with now the low energy domains of maps $\{\boldsymbol{C}-\boldsymbol{C}\}$ and $\{\boldsymbol{S} \boldsymbol{x}-\boldsymbol{C}\}$ (see Figure 7, paper I). The resulting geometries have been optimized in the catalytic site with the minimization protocol already described. At the end of this maltotriose stage, additional minimizations have been carried out after several manual reorientations of primary hydroxyl groups for the substrate rings to explore alternative $g t$ or $t g$ conformations compared to initial $g g$ one. These last calculations have been performed to explore all possible hydrogen bonds between the enzyme and the substrate in the absence of any water molecule in the catalytic site. At this stage, the side chains of enzyme residues in contact with the substrate have been allowed to vary in the minimization procedure.

Binding of a Maltopentaose Fragment. In order to link the catalytic site to other nearby binding subsites, the substrate propagation has been extended up to a pentasaccharide fragment by adding one glucose ring on both sides of the previously modeled maltotriose with the same construction protocol. According to the substrate labeling, rings $\mathbf{A}^{-\mathbf{1}}$ and $\mathbf{D}$ have been linked to rings $\mathbf{A}$ and $\mathbf{C}$, respectively. This new $\left(\mathbf{A}^{\mathbf{- 1}} \mathbf{- A}-\mathbf{B}-\right.$ C-D) fragment occupies contiguous subsites $(\mathbf{- 2}$, $\mathbf{- 1},+\mathbf{1},+\mathbf{2}$, and $\mathbf{+ 3}$ ). However, contrary to maltotriose, all these starting geometries have been minimized with a single minimization procedure $(5000$ iterations, no tethering of the substrate atomic coordinates, freezing of the enzyme heavy atoms). It has been considered that the previously refined rings were sufficiently bound to the catalytic site to prevent any artifactual ejection out of the catalytic cleft during the minimization. But, for a satisfying accuracy of these calculations, an important number of iterations was needed to take into account the increasing molecular weight of the substrate. Finally, manual reorientations of added rings have been performed before final minimizations to confirm the hydrogen-bond network between the two molecules.

\section{RESULTS AND DISCUSSION}

\section{Inhibitor Binding}

From the crystallographic data, the inhibitor has been minimized and the important conformational parameters- $(Q, \theta$, and $\Phi)$ puckering, $(\varphi, \psi)$ torsion angles and $(\tau)$ ring propagation-have been reported in the first column of Tables I, II, and III respectively.

From the puckering parameters, it is possible to grossly classify the ring conformational type. Central ring $\mathbf{B}$ adopts the most stable $\{\boldsymbol{C}\}$ form while the rings at the extremities present deformations. Ring $\mathbf{A}$ has the flattest geometry with an $\theta$ value characteristic of an intermediate $\{\boldsymbol{H}\}$ geometry between forms $\{\boldsymbol{C}\}$ and $\{\boldsymbol{S} \boldsymbol{x}\}$, while $\Phi$ value corresponds to form $\{\boldsymbol{S} \boldsymbol{3}\}$ (see Figure 2, paper I). Therefore, ring $\mathbf{A}$ can be characterized as form $\{\boldsymbol{H} \mathbf{3}\}$. Thus, asymmetric deformations of the two rings are observed on each side of the 
Table I Puckering Parameters of Six-Membered Rings ${ }^{\text {a }}$

\begin{tabular}{|c|c|c|c|c|}
\hline \multicolumn{2}{|c|}{ Puckering Parameters } & \multirow[t]{2}{*}{$\begin{array}{l}\text { Minimized } \\
\text { Inhibitor }\end{array}$} & \multirow[t]{2}{*}{$\begin{array}{l}\text { Modeled } \\
\text { Maltotriose }\end{array}$} & \multirow{2}{*}{$\begin{array}{c}\begin{array}{c}\text { Modeled } \\
\text { Maltopentaose }\end{array} \\
0.55\end{array}$} \\
\hline $\mathbf{A}^{-\mathbf{1}}$ ring & $Q(\AA)$ & & & \\
\hline & $\theta\left({ }^{\circ}\right)$ & & & 5 \\
\hline & $\Phi\left(^{\circ}\right)$ & & & 128 \\
\hline & Zone & & & $\left\{{ }^{4} C_{1}\right\}($ or $\{C\})$ \\
\hline \multirow[t]{4}{*}{ A ring } & $Q(\AA)$ & 0.51 & 0.57 & 0.53 \\
\hline & $\theta\left(^{\circ}\right)$ & 49 & 6 & 27 \\
\hline & $\Phi\left(^{\circ}\right)$ & 131 & 106 & 98 \\
\hline & Form & $\{\mathrm{H} 3\}$ & $\{\boldsymbol{C}\}$ & $\{\boldsymbol{H} 2\}$ or $\{\boldsymbol{C}\}$ \\
\hline \multirow[t]{4}{*}{$\mathbf{B}$ ring } & $Q(\AA)$ & 0.59 & 0.52 & 0.52 \\
\hline & $\theta\left({ }^{\circ}\right)$ & 11 & 12 & 6 \\
\hline & $\Phi\left(^{\circ}\right)$ & 233 & 260 & 271 \\
\hline & Form & $\{C\}$ & $\{C\}$ & $\{C\}$ \\
\hline \multirow[t]{4}{*}{$\mathbf{C}$ ring } & $Q(\AA)$ & 0.54 & 0.55 & 0.65 \\
\hline & $\theta\left({ }^{\circ}\right)$ & 60 & 9 & 92 \\
\hline & $\Phi\left(^{\circ}\right)$ & 196 & 181 & 231 \\
\hline & Form & $\{\mathrm{S} 4\}$ & $\{C\}$ & $\{S 4\}$ \\
\hline \multirow[t]{4}{*}{$\mathbf{D}$ ring } & $Q(\AA)$ & & & 0.52 \\
\hline & $\theta\left(^{\circ}\right)$ & & & 2 \\
\hline & $\Phi\left(^{\circ}\right)$ & & & 194 \\
\hline & Form & & & $\{C\}$ \\
\hline
\end{tabular}

\footnotetext{
${ }^{\text {a }}$ For each ring, the three first lines correspond to puckering parameters whose spherical representation is shown in paper I (Figure 2); the fourth line corresponds to the ring form as defined in paper I from a combination of $\Phi$ pseudorotation phase (Figure 1) and $\theta$ puckering values (Figure 2).
}

catalytic cleavage. Ring $\mathbf{C}$ has a more important $\theta$ value leading to a geometry near to a flexible form and its $\Phi$ value approximately corresponds to zone $\{\boldsymbol{S} 4\}$.

For linkage A-B, the torsion angles $\left(\varphi=13^{\circ}, \psi\right.$ $\left.=-136^{\circ}\right)$ are not consistent with the low energy domains of map $\{\boldsymbol{C}-\boldsymbol{C}\}$ (see Figure 4, paper I). The nearest acceptable zone (domain A: $\varphi=56^{\circ}, \psi$ $=-151^{\circ}$ ) is far enough to conclude that this map is irrelevant for this disaccharide fragment. The ring $\mathbf{A}$ deformation toward form $\{\mathbf{S} \mathbf{3}\}$ is responsible for this phenomenon. Therefore, the most useful map reported in paper I is $\{\boldsymbol{S 3}-\boldsymbol{C}\}$ (see Figure 7, paper I). As mentioned in Table IV of paper I, the corresponding low energy domain is identified as domain $\mathrm{A}^{\prime}$ whose $(\varphi, \psi)$ values can be better compared to experimental ones. In fact, ring $\boldsymbol{A}$ has not a perfect $\{\boldsymbol{S} 3\}$ form but adopts the nearest $\{\boldsymbol{H} \mathbf{3}\}$ form. For linkage $\mathbf{B}-\mathbf{C}$, the torsion angles $\left(\varphi=94^{\circ}, \psi=-121^{\circ}\right)$ satisfactorily correspond to domain B of map $\{\boldsymbol{C}-\boldsymbol{S 4}\}\left(\varphi=107^{\circ}, \psi\right.$ $\left.=-123^{\circ}\right)$. Because of the similarities between maps $\{\boldsymbol{C}-\boldsymbol{S} 4\}$ and $\{\boldsymbol{C}-\boldsymbol{C}\}$, these torsion angles also correspond to domain B of the latter map as well.

The experimental value of the chain propagation parameter $\left(\tau=144^{\circ}\right)$ between rings $\mathbf{A}$ and $\mathbf{B}$ is that expected for domain $\mathrm{A}^{\prime}$ of map $\{\boldsymbol{S} \mathbf{3}-\boldsymbol{C}\}$. The ring $\mathrm{A}$ distortion provokes a more important curvature compared to that calculated $\left(\sim 155^{\circ}\right)$ between two $\{\boldsymbol{C}\}$ forms (see Table V, paper I). The propagation between rings $\mathbf{B}$ and $\mathbf{C}$ is more linear $\left(\tau=155^{\circ}\right)$ corresponding to that expected for domain $\mathrm{B}$ of map $\{\boldsymbol{C}-\boldsymbol{S} 4\}$.

\section{Maltotriose Binding}

Among all minimized solutions, the lowest energy one has a $\{\boldsymbol{C}-\boldsymbol{C}-\boldsymbol{C}\}$ type and the important conformational features are reported in Tables I, II and III. However, another low energy solution (only $5 \mathrm{kcal}$ - mol $^{-1}$ above) derived from the $\{\boldsymbol{C}-\boldsymbol{C}-\boldsymbol{S} \boldsymbol{4}\}$ type has been kept for further calculations.

Substrate Conformation. Contrary to the inhibitor, all three rings adopt the $\{\boldsymbol{C}\}$ form according to the final puckering values. For ring $\mathbf{A}$, this can be explained by the absence of the double bond. It means that, at this stage, the ring $\mathbf{A}$ deformation is not a necessary condition for the glucose docking in subsite $(\mathbf{- 1})$. Similarly for ring $\mathbf{C}$, the best docking solution occurs with the $\{\boldsymbol{C}\}$ form. Interestingly, the second lowest energy solution, with likely a $\{\boldsymbol{S} \mathbf{S}\}$ form $(\mathrm{Q}$ 
Table II Interresidue Torsion Angles ${ }^{a}$

\begin{tabular}{|c|c|c|c|c|c|}
\hline \multicolumn{2}{|c|}{ Rings Junction } & $\begin{array}{l}\text { Minimized } \\
\text { Inhibitor }\end{array}$ & \multirow[t]{2}{*}{$\begin{array}{c}\text { Modeled } \\
\text { Maltotriose }\end{array}$} & \multicolumn{2}{|c|}{$\begin{array}{c}\text { Modeled } \\
\text { Maltopentaose }\end{array}$} \\
\hline \multirow{6}{*}{$\mathbf{A}^{-1}-\mathbf{A}$} & $\varphi\left(^{\circ}\right)$ & & & \multicolumn{2}{|c|}{123} \\
\hline & $\psi\left({ }^{\circ}\right)$ & & & \multicolumn{2}{|c|}{-155} \\
\hline & Map & & & \multicolumn{2}{|c|}{$\boldsymbol{C}-\boldsymbol{H} 2$} or $\{\boldsymbol{C}-\boldsymbol{C}\}$ \\
\hline & Domain & & & $\mathrm{B}$ & B \\
\hline & Theo. $\varphi\left(^{\circ}\right)$ & & & 110 & 114 \\
\hline & Theo $\psi\left(\left(^{\circ}\right)\right.$ & & & -130 & -133 \\
\hline \multirow[t]{6}{*}{ A-B } & $\varphi\left({ }^{\circ}\right)$ & 13 & 43 & \multicolumn{2}{|c|}{35} \\
\hline & $\psi\left({ }^{\circ}\right)$ & -136 & -153 & \multicolumn{2}{|c|}{-150} \\
\hline & Map & $\{\mathrm{S} 3-\mathrm{C}\}$ or $\{\mathrm{S} 3-\boldsymbol{C}\}$ & $\{C-C\}$ & \multicolumn{2}{|c|}{$\boldsymbol{H} 2-\boldsymbol{C}$} or $\{\boldsymbol{C}-\boldsymbol{C}\}$ \\
\hline & Domain & $\mathrm{A}^{\prime} \quad \mathrm{A}$ & A & $\mathrm{A}^{\prime}$ & A \\
\hline & Theo. $\varphi\left(^{\circ}\right)$ & -22 & 56 & 30 & 56 \\
\hline & Theo $\psi\left({ }^{\circ}\right)$ & $-147 \quad-133$ & -151 & -150 & -151 \\
\hline \multirow[t]{6}{*}{ B-C } & $\varphi\left({ }^{\circ}\right)$ & 94 & 100 & \multicolumn{2}{|c|}{109} \\
\hline & $\psi\left({ }^{\circ}\right)$ & -121 & -137 & \multicolumn{2}{|c|}{-142} \\
\hline & Map & $\{C-S 4\}$ & $\{C-C\}$ & \multicolumn{2}{|c|}{$C-S 4$} \\
\hline & Domain & B & B & \multicolumn{2}{|c|}{ B } \\
\hline & Theo. $\varphi\left(^{\circ}\right)$ & 107 & 114 & \multicolumn{2}{|c|}{107} \\
\hline & Theo $\psi\left(\left(^{\circ}\right)\right.$ & -123 & -133 & \multicolumn{2}{|c|}{-123} \\
\hline \multirow[t]{7}{*}{ C-D } & $\varphi\left({ }^{\circ}\right)$ & & & \multicolumn{2}{|c|}{55} \\
\hline & $\varphi\left({ }^{\circ}\right)$ & & & \multicolumn{2}{|c|}{55} \\
\hline & $\psi\left({ }^{\circ}\right)$ & & & \multicolumn{2}{|c|}{-129} \\
\hline & Map & & & \multicolumn{2}{|c|}{$S 4-C$} \\
\hline & Domain & & & \multicolumn{2}{|c|}{$\mathrm{A}$} \\
\hline & Theo. $\varphi\left(^{\circ}\right)$ & & & \multicolumn{2}{|c|}{71} \\
\hline & Theo. $\psi\left({ }^{\circ}\right)$ & & & \multicolumn{2}{|c|}{-132} \\
\hline
\end{tabular}

${ }^{a}$ For each junction, the $(\varphi, \psi)$ values are listed first. Then, theoretical values corresponding to low energy domains of existing maps are reported according to Tables II, III, and IV of paper I.

$=0.65 \AA, \theta=90^{\circ}$, and $\Phi=237^{\circ}$ ), is consistent with the inhibitor ring $\mathbf{C}$ form and can be considered as an alternate docking in subsite $(+\mathbf{2})$.

The glycosidic torsion angles are easily checked on map $\{\boldsymbol{C}-\boldsymbol{C}\}$. For junctions $\mathbf{A}-\mathbf{B}$ and $\mathbf{B}-\mathbf{C}$, the values $\left(\varphi=43^{\circ}, \psi=-153^{\circ}\right.$ and $\varphi=100^{\circ}, \psi=-137^{\circ}$, respectively) satisfactorily correspond to domains $\mathrm{A}$ and B (Table II of paper I). For the former junction, when compared to the inhibitor, the replacement of a $\{\boldsymbol{H}\}\}$ form by a $\{\boldsymbol{C}\}$ one for ring $\mathbf{A}$ leads to a shift in the $(\varphi, \psi)$ space (see Figure 5, paper I), from the $\mathrm{A}^{\prime}$ domain to the nearest $\mathrm{A}$ one.

Docking. In this narrow cleft, alternative ring forms are surprising when comparing the inhibitor and the modeled maltotriose (changes from $\{\mathbf{S} \mathbf{3}\}$ and $\{\boldsymbol{S} \mathbf{S}\}$ to $\{\boldsymbol{C}\}$ for rings $\mathbf{A}$ and $\mathbf{C}$, respectively). In fact, the global shape of these DP3 fragments is not perturbed by the observed ring distortions. As reported in Table III, the corresponding $\tau$ values are very similar (144 ${ }^{\circ}$, $149^{\circ}$ and $155^{\circ}, 163^{\circ}$ for junctions A-B and B-C respectively). For parameter $\Omega$-measuring the rela- tive orientation between two adjacent rings-the values are also close $(-112,-95$ and $-26,-29$ respectively). This means that the three rings of the two molecules have almost same shapes (characterized by $\tau$ values) allowing a very similar docking pattern (characterized by $\Omega$ values) that could be the only one compatible with this environment. Thus, differences in forms for rings $\mathbf{A}$ and $\mathbf{C}$ are possible as long as the general docking scheme is kept. The binding of rings $\mathbf{A}$ and $\mathbf{C}$ on subsites $(\mathbf{- 1})$ and $(\mathbf{+ 2})$ essentially depends on stacking phenomena ${ }^{49-51}$ with $\mathrm{Y}_{51}$ and $\mathrm{W}_{206}$ respectively. As a consequence of these strong stacking interactions, central ring $\mathbf{B}$ is tightly bound into subsite $(+\mathbf{1})$.

\section{Maltopentaose Binding}

From the two lowest energy docking solutions selected at the maltotriose stage, only the one derived from geometry $\{\boldsymbol{C}-\boldsymbol{C}-\boldsymbol{S} 4\}$ leads to the best docking solution for the maltopentaose and the conformational parameters are reported in Tables I-III. 
Table III Chain Propagation Parameter ${ }^{a}$

\begin{tabular}{|c|c|c|c|c|}
\hline Ring Junction & & Inhibitor & $\begin{array}{c}\text { Modeled } \\
\text { Maltotriose }\end{array}$ & $\begin{array}{c}\text { Modeled } \\
\text { Maltopentaose }\end{array}$ \\
\hline \multirow[t]{4}{*}{$\mathbf{A}^{-1}-\mathbf{A}$} & $\tau\left(^{\circ}\right)$ & & & \multirow{2}{*}{$\begin{array}{c}148 \\
\{\boldsymbol{C}-\boldsymbol{H} 2\} \text { or }\{\boldsymbol{C}-\boldsymbol{C}\end{array}$} \\
\hline & Map & & & \\
\hline & Domain & & & B $\quad$ B \\
\hline & Theo. $\tau\left(^{\circ}\right)$ & & & 156 \\
\hline \multirow[t]{4}{*}{ A-B } & $\tau\left(^{\circ}\right)$ & 144 & 149 & 146 \\
\hline & Map & $\{S 3-C\}$ & $\{C-C\}$ & $\{C-C\}$ \\
\hline & Domain & $\mathrm{A}^{\prime}$ & A & A \\
\hline & Theo. $\tau\left({ }^{\circ}\right)$ & 141 & 155 & 155 \\
\hline \multirow[t]{4}{*}{ B-C } & $\tau\left(^{\circ}\right)$ & 155 & 163 & 168 \\
\hline & Map & $\{C-S 4\}$ & $\{C-C\}$ & $\{C-S 4\}$ \\
\hline & Domain & B & B & B \\
\hline & Theo. $\tau\left(^{\circ}\right)$ & 155 & 155 & 155 \\
\hline \multirow[t]{4}{*}{ C-D } & $\tau\left({ }^{\circ}\right)$ & & & 167 \\
\hline & Map & & & $\{S 4-C\}$ \\
\hline & Domain & & & A \\
\hline & Theo. $\tau\left(^{\circ}\right)$ & & & 170 \\
\hline
\end{tabular}

${ }^{a}$ For each junction, the $\tau$ value is listed first. Then, theoretical value corresponding to low energy domains of existing maps is reported according to Table $\mathrm{V}$ of paper I.

Substrate Conformation. The glucose rings are now analyzed from the nonreducing to the reducing end. Ring $\mathbf{A}^{-1}$ situated in one extremity adopts the $\{\boldsymbol{C}\}$ form. For ring $\mathbf{A}$, the initial $\{\boldsymbol{C}\}$ form in the maltotriose has been transformed during minimization to a new conformation intermediate $\left(\theta=27^{\circ}\right)$ between forms $\{\boldsymbol{C}\}$ and $\{\boldsymbol{H} \boldsymbol{x}\}$. As its $\Phi$ value corresponds to zone $\{\boldsymbol{S} 2\}$, this ring could be classified as form $\{\boldsymbol{H} 2\}$. It must be underlined that this deformation is only due to the appending of ring $\mathbf{A}^{\mathbf{- 1}}$. Furthermore, ring $\mathbf{A}$ has an almost flat form (as in the inhibitor case). The initial $\{\boldsymbol{S} 4\}$ form of ring $\mathbf{C}$ is preserved. Contrary to ring $\mathbf{A}$, the ring $\mathbf{C}$ form is not significantly perturbed by the presence of ring $\mathbf{D}$ that also adopts the $\{\boldsymbol{C}\}$ form.

Because of the crucial role of ring $\mathbf{A}$, the consequences of its peculiar form have to be analyzed carefully. Thus, it was decided to draw specific maps $\{\boldsymbol{C}-\boldsymbol{H} 2\}$ and $\{\boldsymbol{H} 2-\boldsymbol{C}\}$ to report the $(\boldsymbol{\varphi}, \psi)$ values measured for the two disaccharide moieties of fragment $\mathbf{A}^{-\mathbf{1}}-\mathbf{A}-\mathbf{B}$. These two maps are shown in Figure 2 while the important conformational features are reported in Table IV.

The low iso-energy contours of map $\{\boldsymbol{C}-\boldsymbol{H} 2\}$ look more similar to those of map $\{\boldsymbol{C}-\boldsymbol{S 5}\}$ than to those of map $\{\boldsymbol{C}-\boldsymbol{S} 2\}$ (see Figure 6, paper I). For the deformations on the nonreducing ring, map $\{\boldsymbol{H} 2-\boldsymbol{C}\}$ is now compared to map $\{\boldsymbol{S} 2-\boldsymbol{C}\}$ (see Figure 7, paper I). While domain B is kept on both maps, domain A of map $\{\boldsymbol{S} 2-\boldsymbol{C}\}$ is significantly displaced on map $\{\boldsymbol{H} 2-$ C). When considering the crude delimitation of the low energy domains in Figure 5 of paper I, the corresponding domain of map $\{\boldsymbol{H} 2-\boldsymbol{C}\}$ could be assimilated to type $\mathrm{A}^{\prime}$, which is consistent with the general tendency of maps $\{\boldsymbol{S} \boldsymbol{x}-\boldsymbol{C}\}$ to generate domain $\mathrm{A}^{\prime}$.

The glycosidic torsion angles are reported in Table II. For junction $\mathbf{A}^{-\mathbf{1}}-\mathbf{A}$, the $(\varphi, \psi)$ values correspond to domain B of map $\{\boldsymbol{C}-\boldsymbol{H} 2\}$. For junction $\mathbf{A}-\mathbf{B}$, the torsion angles $\left(\varphi=35^{\circ}, \psi=-150^{\circ}\right)$ are those found for domain $\mathrm{A}^{\prime}$ of map $\{\boldsymbol{H} 2-\boldsymbol{C}\}$. But compared to the modeled maltotriose, these values are quite similar, which means that the ring $\mathbf{A}$ deformation merely keeps the global shape of this trisaccharide fragment. These general conclusions can be extended to junction B-C where the change from the $\{\boldsymbol{C}\}$ form to $\{\boldsymbol{S 4}\}$ form for ring $\mathbf{C}$ does not significantly modify the torsion angles corresponding to domain $\mathrm{B}$ either for maps $\{\boldsymbol{C}-\boldsymbol{C}\}$ or $\{\boldsymbol{C}-\boldsymbol{S} \boldsymbol{4}\}$. Finally, junction $\mathbf{C}-\mathbf{D}$ has the torsion angles corresponding to domain A of map $\{$ S4-C $\}$.

The $\tau$ values $\left(148^{\circ}\right.$ and $\left.146^{\circ}\right)$ for junctions $\mathbf{A}^{-\mathbf{1}}-\mathbf{A}$ and $\mathbf{A}-\mathbf{B}$ are significantly lower than the others which corresponds to an important curvature of the chain propagation in response to the bend encompassing binding subsites $(\mathbf{- 2}, \mathbf{- 1}$, and $\mathbf{+ 1})$. Furthermore, this curvature is supported by the glycosidic linkages on both sides of ring $\mathbf{A}$ after its deformation. If this ring had kept the initial $\{\boldsymbol{C}\}$ form when adding ring $\mathbf{A}^{-\mathbf{1}}$, the $\tau$ values would have been too high, preventing the global curvature of fragment $\mathbf{A}^{-\mathbf{1}} \mathbf{- A}-\mathbf{B}$ inside the catalytic cleft. After discarding form $\{\boldsymbol{C}\}$, the following $\{\boldsymbol{S} \boldsymbol{x}\}$ low energy forms should be examined. Due 

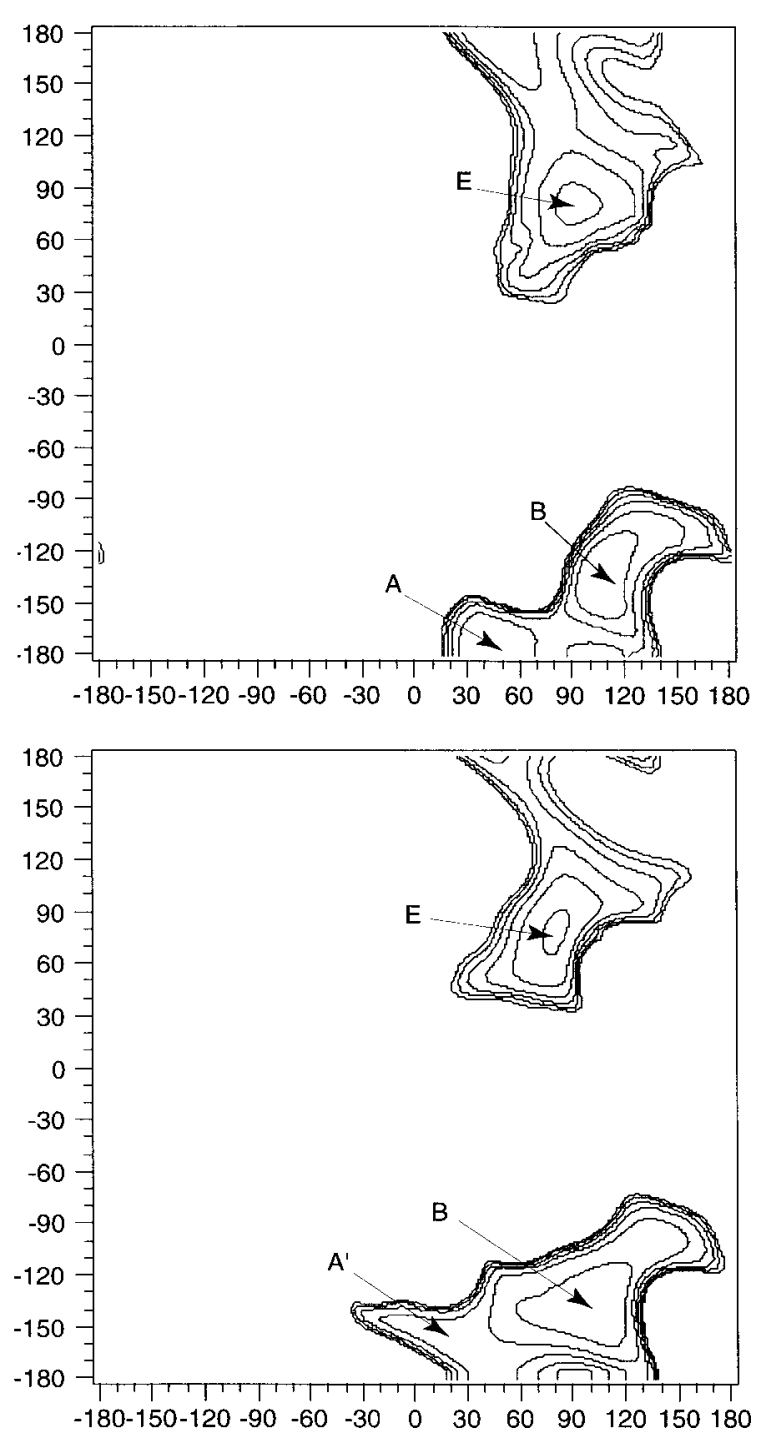

FIGURE 2 Semirelaxed $\{\boldsymbol{C}-\boldsymbol{H} \boldsymbol{2}\}$ (a) and $\{\boldsymbol{H} 2-\boldsymbol{C}\}$ (b) maltose map. The relative iso-energy contours are spaced at $5 \mathrm{kcal} / \mathrm{mol}$ intervals above the absolute minimum until 30 $\mathrm{kcal} / \mathrm{mol} .(\phi, \psi)$ correspond to abscissa and ordinate respectively. The labeling of low energy domains (A, B, and E) is consistent with that adopted in paper I.

to the severe curvature, the potentially acceptable forms should lead to significantly low $\tau$ values for the domains of both maps $\{\boldsymbol{S} \boldsymbol{x}-\boldsymbol{C}\}$ and $\{\boldsymbol{C}-\boldsymbol{S} \boldsymbol{x}\}$. Under this criterion and according to Table $\mathrm{V}$ of paper I, forms $\{\mathbf{S} 1\},\{\mathbf{S} 2\},\{\mathbf{S} 4\},\{\mathbf{S} 5\}$, and $\{\mathbf{S 6}\}$ should be discarded because of the high $\tau$ values for maps $\{\boldsymbol{S} \boldsymbol{x}-\boldsymbol{C}\}$, while form $\{\mathbf{S 3}\}$ is not acceptable because of the high $\tau$ values corresponding to all domains of map $\{\boldsymbol{C}-\boldsymbol{S 3}\}$. Thus, ring A must adopt another flexible form (close to geometry $\{\boldsymbol{H} 2\}$ as suggested by our calculations).

In the optimized substrate, the glucose rings have the $(t g, g g, g g, t g, t g)$ primary hydroxyl group orien- tations from the nonreducing to the reducing rings. The main intrasubstrate hydrogen bonds or interesting contacts are reported in Table V. For comparison, the equivalent distances measured on the inhibitor are also mentioned. The orientation change for ring $\mathbf{C}$ (from $g t$ to $t g$ for inhibitor to maltopentaose) allows a better substrate energy with two additional hydrogen bonds with O5 (ring B) and glycosidic (B-C) oxygen atoms. Furthermore, the two extreme rings are hydrogen bonded to the adjacent ones, increasing the rigidity of this amylose fragment in the narrow cleft.

Comparison with Substrate Conformation in the PPA Binding Site. This substrate conformation is now compared to another pentasaccharide fragment modeled in the catalytic site of PPA. ${ }^{52}$ However, one must beware of the differences in ring labeling when referring to equivalent subsite numbering. In PPA, the rings are labeled from $\mathbf{A}_{\mathbf{P P A}}$ to $\mathbf{E}_{\mathbf{P P A}}$ but the corresponding subsites span from $(\mathbf{- 3})$ to $(+\mathbf{2})$. Therefore, this one glucose ring shift leads to the following correspondence (rings $\mathbf{B}_{\mathbf{P P A}}, \mathbf{C}_{\mathbf{P P A}}, \mathbf{D}_{\mathbf{P P A}}, \mathbf{E}_{\mathbf{P P A}}$ in $\mathrm{PPA}$, and rings $\mathbf{A}^{-\mathbf{1}}, \mathbf{A}, \mathbf{B}, \mathbf{C}$ in AMY2). In PPA, most glucose rings have been found in form $\{\boldsymbol{C}\}$ except for $\mathbf{C}_{\mathbf{P P A}}$. For this ring, the $\theta$ value $\left(\sim 20^{\circ}\right)$ is quite similar to that found for our corresponding ring $\mathbf{A}$ $\left(\sim 27^{\circ}\right)$. Since the other puckering values are missing, these rings are likely to have the same conformation mainly characterized by a significant flattening found in the corresponding conduritol residue of the inhibitor. But contrary to what is claimed in the PPA context, our results show that the ring $\mathbf{A}$ deformation, induced by appending ring $\mathbf{A}^{-\mathbf{1}}$, is essential for the docking of both rings $\mathbf{A}$ and $\mathbf{A}^{-1}$. The bend of the catalytic cleft observed on both AMY2 and PPA contexts is centered on ring $\mathbf{A}$ (or $\mathbf{C}_{\mathbf{P P A}}$ ) and leads to this ring deformation whose flattening is also important to explain the catalytic mechanism. ${ }^{39,40}$ Terminal ring $\mathbf{E}_{\mathbf{P P A}}$ adopts from $\{\boldsymbol{C}\}$, which is consistent with the ring $\mathbf{C}$ conformation of our modeled maltotriose.

Docking. The most important short distances between the modeled substrate and the enzyme are reported in Table VI with a cutoff distance of $3.4 \AA$. The corresponding values from the inhibitor complexed with the enzyme are also reported when existing. This barley $\alpha$-amylase/maltopentaose docking is characterized by strong interactions between the enzyme and the substrate, consistent with well-defined subsites. Furthermore, all short distances are comparable to those experimentally identified by Kadziola. ${ }^{30,35}$

Rings $\mathbf{A}$ and $\mathbf{C}$ are especially tightly bound with hydrogen bonds but mainly with stacking phenomena 
Table IV Conformational Features of "Semi-Relaxed" Maps $\{\mathrm{C}-\mathrm{H} 2\}$ and $\{\mathrm{H} 2-\mathrm{C}\}^{\mathrm{a}}$

\begin{tabular}{llcccc}
\hline & & \multicolumn{3}{c}{ Low Energy Domain } \\
\cline { 3 - 6 } Map & & $\mathrm{A}^{\prime}$ & $\mathrm{A}$ & $\mathrm{B}$ & $\mathrm{E}$ \\
\hline \multirow{2}{*}{$\boldsymbol{C}-\boldsymbol{H} 2$} & Energy $(\mathrm{kcal} / \mathrm{mol})$ & & 19.1 & 13.3 & 17.2 \\
& $\phi\left(^{\circ}\right)$ & & 41 & 108 & 91 \\
& $\varphi\left(^{\circ}\right)$ & & -179 & -133 & 81 \\
& $\tau\left(^{\circ}\right)$ chain propagation & & 156 & 161 & 166 \\
& Pucker $Q(\AA)$ & 0.49 & 0.51 & 0.51 \\
& $\theta\left(^{\circ}\right)$ & & 51 & 53 & 52 \\
& $\Phi\left(^{\circ}\right)$ & & 178 & 183 & 181 \\
$\{\boldsymbol{H} 2-\boldsymbol{C}\}$ & Energy (kcal/mol) & 9.4 & & 8.0 & 12.2 \\
& $\phi\left(^{\circ}\right)$ & 20 & & 107 & 80 \\
& $\varphi\left(^{\circ}\right)$ & -150 & & -135 & 79 \\
& $\tau\left(^{\circ}\right)$ chain propagation & 158 & & 159 & 160 \\
& Pucker $Q(\AA)$ & 0.50 & & 0.51 & 0.51 \\
& $\theta\left(^{\circ}\right)$ & 50 & & 49 & 49 \\
& $\Phi\left(^{\circ}\right)$ & 146 & & 158 & 159 \\
\hline
\end{tabular}

${ }^{\mathrm{a}}$ For each low energy domain, data of the dimeric moiety are listed first. The relative energies, the $(\phi, \varphi)$ glycosidic angles and the $(\tau)$ chain propagation definitions are those defined in paper I. In the last lines, the reported puckering parameters are those of the flexible form.

(Y51, ${ }^{\dagger}$ W206 respectively). Therefore, intermediate ring $\mathbf{B}$ is supposed to be firmly attached in its subsite with two hydrogen bonds. The catalytic residues are fully involved in the binding of rings $\mathbf{A}$ and $\mathbf{B}$ of

\footnotetext{
${ }^{\dagger}$ In the following discussion, the residues without subscript refer to barley $\alpha$-amylase 2.2 while those with subscripts refer to the corresponding enzymes (i.e., W206, $\mathrm{Y}_{\mathrm{TAA}} 155, \mathrm{Y}_{\mathrm{PPA}} 151$ for the barley, Taka, and porcine pancreatic amylases, respectively).
}

maltopentaose or the inhibitor as well, with almost the same hydrogen-bond network except for the glycosidic A-B oxygen atom. For the substrate this atom is hydrogen bonded with D289 while the nitrogen atom of the inhibitor points toward alternate E204. The global orientation of maltopentaose in the catalytic site, as represented by nearby residues listed in Table IV, is shown in Figure 3.

Table V Close Intrasubstrate Distances ${ }^{\text {a }}$

\begin{tabular}{|c|c|c|c|}
\hline \multicolumn{2}{|l|}{ Hydrogen Bonds } & \multirow{2}{*}{$\begin{array}{c}\text { Modeled } \\
\text { Maltopentaose, } \\
\text { Dist. (̊̊) }\end{array}$} & \multirow{2}{*}{$\begin{array}{c}\text { Crystal } \\
\text { Inhibitor, } \\
\text { Dist. (̊) }\end{array}$} \\
\hline Atom 1 & Atom 2 & & \\
\hline $\mathrm{O} 4\left(\mathbf{A}^{-1}\right.$ ring $)$ & O6 tg $\left(\mathbf{A}^{-1}\right.$ ring $)$ & 2.8 & \\
\hline $\mathrm{O} 2\left(\mathbf{A}^{-1}\right.$ ring $)$ & $\mathrm{O} 3$ (A ring) & 2.7 & \\
\hline $\mathrm{O} 2$ (B ring) & $\mathrm{O} 3$ ( $\mathbf{C}$ ring $)$ & 2.9 & 3.3 \\
\hline \multirow[t]{2}{*}{ O5 (B ring) } & O6 tg ( $\mathbf{C}$ ring $)$ & 3.0 & \\
\hline & O6 $g g(\mathbf{C}$ ring $)$ & & 4.9 \\
\hline O6 $g g$ (B ring) & O6 tg (C ring) & 2.9 & \\
\hline \multirow[t]{2}{*}{$\mathrm{O}(\mathbf{B}-\mathbf{C}$ rings $)$} & O6 tg (C ring) & 2.9 & \\
\hline & O6 $g t$ ( $\mathbf{C}$ ring $)$ & & 4.3 \\
\hline \multirow[t]{2}{*}{ O5 ( $\mathbf{C}$ ring $)$} & O6 tg (C ring) & 3.7 & \\
\hline & O6 gt $(\mathbf{C}$ ring $)$ & & 2.7 \\
\hline $\mathrm{O} 2$ ( $\mathbf{C}$ ring $)$ & O6 tg (D ring) & 3.2 & \\
\hline
\end{tabular}

${ }^{\text {a }}$ All potential hydrogen bonds present inside the modeled or experimentally observed substrate are listed. The primary hydroxyl group orientations are explicitly mentioned. 
Table VI Substrate (inhibitor)-Enzyme Short Distances ${ }^{\text {a }}$

\begin{tabular}{|c|c|c|c|}
\hline \multicolumn{2}{|l|}{ Hydrogen Bonds } & \multirow{2}{*}{$\begin{array}{c}\text { Modeled } \\
\text { Maltopentaose, } \\
\text { Dist. (̊) }\end{array}$} & \multirow{2}{*}{$\begin{array}{c}\text { Crystal } \\
\text { Inhibitor, } \\
\text { Dist. (A) }\end{array}$} \\
\hline Atom 1 & Atom 2 & & \\
\hline $\mathrm{O} 2\left(\mathbf{A}^{-1}\right.$ ring $)$ & OE1 (Q 294) & 2.6 & \\
\hline $\mathrm{O} 2\left(\mathbf{A}^{-1}\right.$ ring $)$ & NE2 (Q 294) & 3.4 & \\
\hline $\mathrm{O} 3\left(\mathbf{A}^{-1}\right.$ ring $)$ & OE1 (Q 294) & 2.9 & \\
\hline $\mathrm{O} 2$ (A ring) & NH1 (R 177) & 3.2 & 3.0 \\
\hline $\mathrm{O} 2$ (A ring) & NE2 (H 288) & 3.1 & 2.9 \\
\hline $\mathrm{O} 2$ (A ring) & OD2 (D 289) & 2.8 & 2.8 \\
\hline O3 (A ring) & NE2 (H 288) & 3.9 & 2.8 \\
\hline O3 (A ring) & OD1 (D 289) & 3.3 & 2.8 \\
\hline O5 (A ring) & OD2 (D 179) & 3.2 & - \\
\hline O6 $g g$ (A ring) & $\mathrm{O}(\mathbf{Y}$ 51) $[\mathbf{s}]$ & 3.2 & 3.2 \\
\hline O6 $g g$ (A ring) & NE2 (H 92) & 3.3 & 3.2 \\
\hline O6 $g g$ (A ring) & OD2 (D 179) & 2.8 & 2.9 \\
\hline $\mathrm{O}(\mathbf{A}-\mathbf{B}$ rings $)$ & OE2 (E 204) & 3.9 & \\
\hline N (A-B rings) & & & 3.4 \\
\hline $\mathrm{O}$ (A-B rings) & OD2 (D 289) & 2.9 & \\
\hline N (A-B rings) & & & 3.2 \\
\hline $\mathrm{O} 2$ (B ring) & O (W 206) & 3.4 & 3.8 \\
\hline O3 (B ring) & OE2 (E 204) & 2.7 & 2.6 \\
\hline $\mathrm{O} 2$ ( $\mathbf{C}$ ring $)$ & NE1 (W 206) [s] & 3.3 & 5.2 \\
\hline $\mathrm{O} 2$ ( $\mathbf{C}$ ring) & $\mathrm{O}(\mathbf{T} 207)$ & 3.2 & 4.7 \\
\hline $\mathrm{O} 2$ ( $\mathbf{C}$ ring $)$ & N (S 208) & 3.4 & 3.6 \\
\hline $\mathrm{O} 2$ ( $\mathbf{C}$ ring $)$ & OG (S 208) & 3.7 & 3.2 \\
\hline $\mathrm{O} 3$ ( $\mathbf{C}$ ring) & NZ (K 182) & 3.2 & 3.0 \\
\hline $\mathrm{O} 3$ ( $\mathbf{C}$ ring) & $\mathrm{O}(\mathbf{W}$ 206) $[\mathbf{s}]$ & 2.7 & 2.8 \\
\hline O6 tg ( $\mathbf{C}$ ring $)$ & S (M 296) & 3.2 & \\
\hline O6 gt ( $\mathbf{C}$ ring) & & & 3.6 \\
\hline $\mathrm{O}(\mathbf{C}-\mathbf{D}$ rings $)$ & OG (S 208) & 2.8 & \\
\hline O6 tg (D ring) & NE1 (W 206) & 3.1 & \\
\hline
\end{tabular}

${ }^{\text {a }}$ All distances up to $3.4 \AA$ between the modeled (or experimentally observed) substrate and the enzyme are reported. The stacking phenomena are mentioned with the $[s]$ labeling.

Comparison with Other $\alpha$-Amylase Dockings. It must also be pointed out that all residues mentioned in these binding interactions belong to conserved sequences in known amylases, ${ }^{26,27,53,54}$ which enhances the reliability of this modeling work. Nevertheless, detailed comparisons must be done cautiously because of some differences in the catalytic environment. For example in PPA, the modeled pentasaccharide fragment is supposed to cover all the 5 identified subsites contrary to barley $\alpha$-amylase where 10 subsites have been determined.

Catalytic residues D179, E204, and D289 of barley $\alpha$-amylase are also found in porcine pancreatic, human pancreatic, Taka amylases, or other related enzymes as well. For example, in the PPA and TAA cases, the equivalent catalytic triads are identified ( $\mathrm{D}_{\mathbf{P P A}} 197, \mathrm{E}_{\mathbf{P P A}} 233, \mathrm{D}_{\mathbf{P P A}} 300$ and $\mathrm{D}_{\mathrm{TAA}} 206$, $\mathrm{E}_{\mathrm{TAA}} 230, \mathrm{D}_{\mathrm{TAA}} 297$, respectively) with almost the same hydrogen-bond network with the glucose rings.
The superimposition of these structures only on the basis of the backbone atoms of these catalytic residues reveals 3D topographical homologies for some other conserved residues. In terms of stacking phenomena, Y51 (subsite -1) is tightly bound to ring $\mathbf{A}$ as does equivalent $\mathrm{Y}_{\mathrm{PPA}} 62$ with the $\mathrm{C}_{\mathrm{PPA}}$ ring ${ }^{52}$ or could do $\mathrm{Y}_{\mathrm{TAA}} 82$ with the corresponding glucose $\mathrm{TAA}_{\mathrm{TA}}$ ring. Similarly, $\mathrm{H} 92$ and $\mathrm{H} 288,{ }^{55}$ which are involved in hydrogen bonds with ring $\mathbf{A}$, are known to play an important role in the endo-type specificity as do the same amino acid residues in PPA $\left(\mathrm{H}_{\mathrm{PPA}} 101\right.$ and $\left.\mathrm{H}_{\mathrm{PPA}} 299\right)$ or in TAA $\left(\mathrm{H}_{\mathrm{TAA}} 122\right.$ and $\left.\mathrm{H}_{\mathrm{TAA}} 296\right)$. Finally, $\mathrm{K} 182$ and $\mathrm{K}_{\mathrm{PPA}} 200$ are well superimposed to $\mathrm{K}_{\mathrm{TAA}} 209$ and the important positive charge character ${ }^{56,57}$ of the later can be extrapolated to the former two. More interestingly, residues not conserved in $\alpha$-amylases can have a similar function. For example, W206 is responsible for the stacking of ring $\mathbf{C}$ in subsite (+2) like the corresponding residues in Taka 


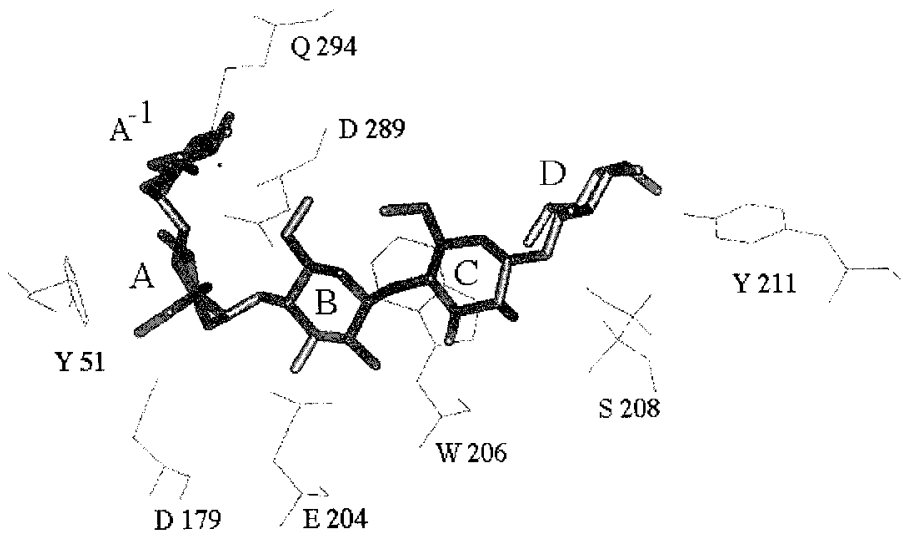

FIGURE 3 Maltopentaose docking and topography of the catalytic cleft. For the enzyme, only residues (lines representation) having short distance contacts with the substrate are shown (see Table V). Residues Y51 and W206 are strongly stacked to A and $\mathbf{C}$ glucose rings, respectively.

amylase and $\mathrm{PPA}^{52}\left(\mathrm{Y}_{\mathrm{TAA}} 155\right.$ and $\mathrm{Y}_{\mathrm{PPA}} 151$ respectively) but with the other side of the glucose ring.

Confrontation with Another Crystal Structure. An experimental feature could indirectly confirm this docking study. Another crystal structure of barley $\alpha$-amylase has been refined by Vallée ${ }^{58}$ at $2.3 \AA$ resolution but without any substrate fragment or inhibitor inside the main binding domain. Some water molecules filling the catalytic cleft have been located, which gives very helpful information about oxygen positions as centers of hydrogen bonds. Based on backbone residues, the superimposition of the two enzyme structures ( $r m s=0.28 \AA$ ) yields to potent information about the location of experimental and modeled oxygen atoms in the catalytic cleft. A significant number of oxygen atoms coincide. Furthermore, as can be seen in Table VII, the pair atomic distance values are satisfactorily low, regarding of possible flexibility of the catalytic environment in the different contexts. The superimposed substrate oxygen atoms are intraring and glycosidic ones as well. Except for the glycosidic (B-C) atom, all of them are mentioned (most of them with several partners) in Table VI of short substrate-enzyme distances, which confirms their role in the hydrogen bonding network. This (B-C) oxygen atom, even well superimposed on an experimental water molecule, is not hydrogen bonded with enzyme residues neither in the substrate nor in the inhibitor complex. In fact, the corresponding experimental water molecule is hydrogen bonded to another water molecule, which is itself bound to enzyme oxygen atom (W 206) leading to an alternate HB system.

\section{CONCLUSIONS}

As a continuation of paper I, this systematic docking study has been performed with tools developed earlier. For example, maps $\{\boldsymbol{C}-\boldsymbol{S} \boldsymbol{x}\}$ or $\{\boldsymbol{S} \boldsymbol{x}-\boldsymbol{C}\}$ are essential for the construction of the substrate and for the docking understanding. From experimental data (inhibitor $(\alpha$-amylase complex), a trisaccharide, then a pentasaccharide substrate fragment, have been docked into the main barley $\alpha$-amylase cleft on either side of the catalytic triad. In spite of the systematic approach used, the uniqueness of maltopentaose docking solution and to a certain extent that of the maltotriose suggests the specificity of the catalytic mechanism in terms of steric hindrances in the cleft near the triad. Any substrate or inhibitor chain should respect a rather strict topography to accommodate the catalytic surrounding.

The maltotriose docking shows that a glucose ring deformation in subsites $(-\mathbf{1})$ and $(\boldsymbol{+} \mathbf{2})$ is not neces-

Table VII Distances Between the Modeled Maltopentaose and the Observed Water Oxygen Atoms

\begin{tabular}{lc}
\hline $\begin{array}{c}\text { Substrate } \\
\text { Atom }\end{array}$ & $\begin{array}{c}\text { Distance } \\
(\AA)\end{array}$ \\
\hline O2 (A ring) & 1.2 \\
O3 (A ring) & 0.8 \\
O6 gg (A ring) & 0.4 \\
O (A-B rings) & 0.7 \\
O (B-C rings) & 0.5 \\
O3 (C ring) & 1.3 \\
O (C-D rings) & 1.0 \\
O6 tg (D ring) & 1.2 \\
\hline
\end{tabular}


sary for strong stacking phenomena, which appears as the crucial binding step just before the cleavage. Therefore, if it is admitted that the flattening of ring $\mathbf{A}$ into subsite $(\mathbf{- 1})$ is vital for the catalytic process, it must be concluded that maltotriose could inhibit competitively the action of $\alpha$-amylases. ${ }^{59}$

In a subsequent stage, the extension to the maltopentaose docking suggests that the ring $\mathbf{A}$ deformation is due to the appending of $\operatorname{ring} \mathbf{A}^{-1}$. If the $\{\boldsymbol{C}\}$ form was kept, the additional ring would dramatically collide with some enzyme residues whatever the glycosidic torsion angles are in the four low energy domains of map $\{\boldsymbol{C}-\boldsymbol{C}\}$. Interestingly, W9, which is involved in all virtual collisions, is a very conserved residue in $\alpha$-amylases. It can be suggested that the enzyme bend corresponding to subsites $(\mathbf{- 2}, \mathbf{- 1}, \mathbf{+ 1})$ is particularly well designed for the $\alpha-(1,4)$ hydrolysis. When an amylose fragment is trapped inside the cleft, a dynamical motion of the vicinal enzyme residues could force the substrate chain to be deformed following the catalytic bend. Thus, the ring A distortion can be interpreted as the substrate response to this kink whose main consequence is its flattening, necessary for the cleavage mechanism. More generally, this means that the rough sequence (binding, specific ring deformation, catalytic mechanism) could be a general protocol for this catalytic machinery.

In the catalytic cleft delimited by five contiguous subsites, all important residues involved in the binding and in the catalytic process have been identified. The short distance contacts between the substrate and the enzyme have been listed and a combination of stacking phenomena and hydrogen-bonding networks is responsible for this strong docking. In the absence of experimental evidence, the comparison with a crystal structure with no inhibitor inside the catalytic cleft gives encouraging presumptions about the validity of the proposed model.

Further studies on barley $\alpha$-amylase are already undertaken in two directions. From a static point of view, the extension of the number of substrate rings is performed to fully cover the catalytic cleft and therefore unambiguously characterize the 10 subsites mentioned in the literature. ${ }^{24,26,37}$ From a dynamical point of view, the understanding of the motion of all important residues already identified is another necessary step toward the explanation of the catalytic process at an atomic level before any rational biological investigations.

\section{REFERENCES}

1. Matsuura, Y.; Kunusoki, M.; Harada, W.; Kakudo, M. J Biochem 1984, 95, 697-702.
2. Swift, H. J.; Brady, L.; Derewenda, Z. S.; Dodson, E. J.; Dodson, G. G.; Turkenburg, J. P.; Wilkinson, A. J. Acta Crystallogr Section B 1991, 47, 535-544.

3. Buisson, G.; Duée, E.; Haser, R.; Payan, F. EMBO J 1987, 6, 3909-3916.

4. Qian, M.; Haser, R.; Payan, F. J Mol Biol 1993, 231, 785-799.

5. Qian, M.; Haser, R.; Buisson, G.; Duée, E.; Payan, F. Biochemistry 1994, 33, 6284-6294.

6. Boel, E.; Brady, L.; Brzozowski, A. M.; Derewenda, Z.; Dodson, G. G.; Jensen, V. J.; Petersen, S. B.; Swift, H.; Thim, L.; Woldike, H. F. Biochemistry 1990, 29, 6244-6249.

7. Brady, R. L.; Brzozowski, A. M.; Derewenda, Z. S.; Dodson, E. J.; Dodson, G. G. Acta Crystallogr Section B 1991, 47, 527-535.

8. Machius, M.; Wiegand, G.; Huber, R. J Mol Biol 1995, 246, 545-559.

9. Brayer, G. D.; Luo, Y.; Withers, S. G. Protein Sci 1995, 4, 1730-1742.

10. Ramasubbu, N.; Bhandary, K. K.; Scannapieco, F. A.; Levine, M. J. Proteins Struct Funct Gen 1991, 11, 230-232.

11. Ramasubbu, N.; Paloth, V.; Luo, Y.; Brayer, G. D.; Levine, M. J. Acta Crystallogr Section D 1996, 52, 435-446.

12. Aghajari, N.; Feller, G.; Gerday, C.; Haser, R. Protein Sci 1998, 7, 564-572.

13. Svensson, B.; Mundy, J.; Gibson, R. M.; Svendsen, I. Carlsberg Res Commun 1985, 50, 15-22.

14. Jones, R. L.; Jacobsen, J. V. Int Rev Cytol 1991, 125, 49-88.

15. Rogers, J. C.; Milliman, C. J Biol Chem 1983, 258, 8169-8174.

16. Rogers, J. C. J Biol Chem 1985, 260, 3731-3738.

17. Bertoft, E.; Andtfolk, C.; Kulp, S. E. J Inst Brew 1984, 90, 298-302.

18. Bush, D. S.; Sticher, L.; Van Huystee, R. B.; Wagner, D.; Jones, R. L. J Biol Chem 1989, 264, 19392-19398.

19. Rodenburg, K. W.; Juge, N.; Guo, X. J.; Søgaard, M.; Chaix, J. C.; Svensson, B. Eur J Biochem 1994, 221, 227-284.

20. MacGregor, A. W. Cereal Chem 1978, 55, 754-765.

21. MacGregor, A. W.; Ballance, D. L. Cereal Chem 1980, 57, 397-402.

22. MacGregor, A. W.; Morgan, J. E. Cereal Foods World 1986, 31, 688-693.

23. Søgaard, M.; Svensson, B. Gene 1990, 94, 173-179.

24. Ajandouz, E. H.; Abe, J.; Svensson, B.; Marchis-Mouren, G. Biochim Biophys Acta 1992, 1159, 193-202.

25. MacGregor, A. W.; Morgan, J. E.; MacGregor, E. A. Carbohydr Res 1992, 227, 301-313.

26. MacGregor, A. W. J Protein Chem 1988, 7, 399-415.

27. Svensson, B. FEBS Lett 1988, 230, 72-76.

28. Friedberg, F. FEBS Lett 1983, 152, 139-140.

29. Kadziola, A.; Abe, J.; Svensson, B.; Haser, R. J Mol Biol 1994, 239, 104-121. 
30. Kadziola, A. PhD thesis, University of Copenhagen/ CNRS Marseille, 1993.

31. Svensson, B. Plant Mol Biol 1997, 25, 141-157.

32. Farber, G. K.; Petsko, G. A. Trends Biochem Sci 1990, 15, 228-234.

33. Farber, G. K. Curr Opin Struct Biol 1993, 3, 409-412.

34. Janecek, S.; Svensson, B.; Henrissat, B. J Mol Evol 1997, 45, 322-331.

35. Kadziola, A.; Søgaard, M.; Svensson, B.; Haser, R. J Mol Biol 1998, 278, 205-217.

36. Søgaard, M.; Kadziola, A.; Haser, R.; Svensson, B. J Biol Chem 1993, 268, 22480-22484.

37. MacGregor, E. A.; MacGregor, A. W. Carbohydr Res 1985, 142, 223-236.

38. André, G.; Buléon, A.; Vallée, F.; Juy, M.; Haser, R.; Tran, V. Biopolymers 1996, 39, 737-751.

39. Truscheit, E.; Frommer, W.; Junge, B.; Müller, L.; Schmidt, D. D.; Wingender, W. Angew Chem Int Ed Engl 1981, 20, 744-761.

40. Sinnott, M. L. Chem Rev 1990, 90, 1171-1202, and references therein.

41. Tao, B. Y.; Reilly, P. J.; Robyt, J. F. Biochim Biophys Acta 1989, 995, 214-220.

42. Kuroki, R.; Weaver, L. H.; Matthews, B. W. Science 1993, 262, 2030-2033.

43. Ford, L. O.; Johnson, L. N.; Machin, P. A.; Phillips, D. C.; Tjian, R. J Mol Biol 1974, 88, 349-371.

44. White, A.; Rose, D. R. Curr Opin Struct Biol 1997, 7, 645-651.
45. Ha, S. N.; Madsen, L. J.; Brady, J. W. Biopolymers 1988, 27, 1927-1952.

46. Tran, V.; Buléon, A.; Imberty, A.; Perez, S. Biopolymers 1989, 28, 679-69.

47. Dinur, U.; Hagler, A. T. (1991), Review of Computational Chemistry Vol 2, Lipkowitz, K. B.; Boyd, D. B., Eds, VCH, New York, chap. 4.

48. Davies, G. J.; Wilson, K. S.; Henrissat, B. Biochem J 1997, 321, 557-559.

49. Quiocho, F. A. Ann Rev Biochem 1986, 55, 287-315.

50. Quiocho, F. A. Pure Appl Chem 1989, 61, 12931306.

51. Vyas, N. K. Curr Opin Struct Biol 1991, 1, 732-740.

52. Casset, F.; Imberty, A.; Haser, R.; Payan, F.; Pérez, S. Eur J Biochem 1995, 232, 284-293.

53. Janecek, S. Biochem J 1992, 288, 1069-1070.

54. Janecek, S. Eur J Biochem 1994, 224, 519-524.

55. Nakatani, H.; Hamaguchi, K.; Ishikawa, K. Carbohydr Res 1994, 257, 155-161.

56. Nagashima, T.; Tada, S.; Kitamoto, K.; Gomi, K.; Kumagai, C.; Toda, H. Biosci Biotech Biochem 1992, 56, 207-210.

57. Kobayashi, M.; Miura, M.; Ichishima, E. Biochem Biophys Res Commun 1992, 183, 321-326.

58. Vallée, F. (1996), PhD thesis, University of Paris XI/ CNRS Marseille.

59. Elodi, P.; Mora, S.; Krysteva, M. Eur J Biochem 1972, 24, 577-582. 